\title{
Review Article \\ miR-30 Family: A Promising Regulator in Development and Disease
}

\author{
Ling Mao $\mathbb{D}^{1,2}$ Shiming Liu, ${ }^{1,2}$ Lin Hu, ${ }^{1,2}$ Li Jia, ${ }^{1,2}$ Hairong Wang, \\ Mengmeng Guo, ${ }^{1,2}$ Chao Chen, ${ }^{1,2}$ Yun Liu, ${ }^{2}$ and Lin Xu ${ }^{1,2}$ \\ ${ }^{1}$ Special Key Laboratory of Gene Detection \& Therapy of Guizhou Province, Zunyi Medical College, Zunyi, Guizhou 563003, China \\ ${ }^{2}$ Guizhou Provincial College-Based Key Lab for Tumor Prevention and Treatment with Distinctive Medicines, \\ Zunyi Medical College, Zunyi, Guizhou 563003, China
}

Correspondence should be addressed to Lin Xu; xulinzhouya@163.com

Received 13 January 2018; Accepted 18 April 2018; Published 29 May 2018

Academic Editor: Stephen H. Safe

Copyright (C) 2018 Ling Mao et al. This is an open access article distributed under the Creative Commons Attribution License, which permits unrestricted use, distribution, and reproduction in any medium, provided the original work is properly cited.

MicroRNAs (miRNAs) are small noncoding RNAs that negatively regulate posttranscriptional expression of target genes. Accumulating evidences have demonstrated that the miR-30 family, as a member of microRNAs, played a crucial regulating role in the development of tissues and organs and the pathogenesis of clinical diseases, which indicated that it may be a promising regulator in development and disease. This review aims to clarify the current progress on the regulating role of miR-30 family in tissues and organs development and related disease and highlight their research prospective in the future.

\section{Introduction}

MicroRNAs (miRNAs) are a family of 20 25-nucleotide small RNAs that generated from primary miRNA (primiRNA) transcribed by RNA polymerase II (Pol II). In the nucleus, the RNase III endonuclease Drosha and the double-stranded RNA-binding domain (dSRBD) protein DGCR8/Pasha cut one strand of the stem of the pri-miRNA hairpin and liberate a 70-nucleotide stem-loop called a "pre-miRNA." Exportin-5 transports the pre-miRNA into the cytoplasm and Dicer cuts pre-miRNA, together with the dSRBD protein TRBP/Loquacious, to generate the miRNA duplex. The miRNA strand is loaded into an Argonautecontaining RNA-induced silencing complex (RISC), which recognizes target mRNAs and commonly results in translational inhibition or destabilization of the target mRNA [1-3]. Up to now, miRNAs have been well documented as critical regulator in the development of tissues and organs and the pathogenesis of clinical diseases $[4,5]$.

The microRNA-30 (miR-30) family is an important member of miRNA family, which contains five members and 6 mature miRNA molecules (namely, miR-30a, miR-30b, miR30c-1, miR-30c-2, miR-30d, and miR-30e) and is encoded by six genes located on human chromosome 1, 6, and 8 (Figure 1). These mature miRNAs share a common seed sequence near the $5^{\prime}$ end but possess different compensatory sequences near the $3^{\prime}$ end (Table 1). These different compensatory sequences allow miR-30 family members to target different genes and pathways, thus performing corresponding biological function [6]. Recent studies have shown that miRNA-30 family played an important regulatory role in tissues and organs development, as well as related clinical diseases pathogenesis.

\section{2. miR-30 Family and Tissue and Organ Development}

2.1. miR-30 Family and Bone Tissue. As early as in 2008, Li et al. reported that the expression of miR-30a and miR-30d decreased significantly in the differentiation of mesenchymal stem cell $\mathrm{C} 2 \mathrm{C} 12$ induced by bone morphogenetic protein2 (BMP-2) [7]. Subsequently, Wu et al. further discovered that miR-30 family members (including miR-30a, miR-30b, miR-30c, and miR-30d) could target transcription signaling molecule SMAD family member 1 (Smad1) and runt-related transcription factor 2 (Runx2) and negatively regulated BMP-2-induced differentiation of osteoblastic cells. However, 


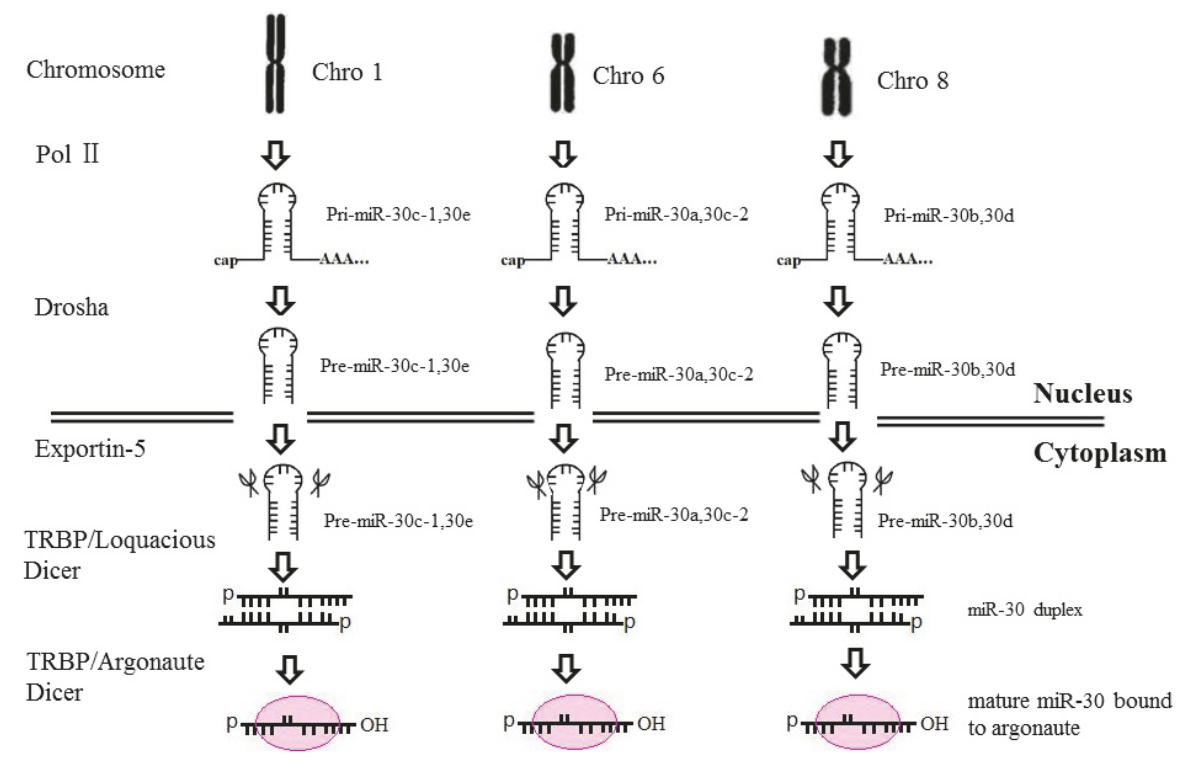

FIgURE 1: The biogenesis of miR-30 family.

the expression of miR-30e did not change in osteoblastic cells with BMP-2 stimulation, indicating that miR-30 family played an important role in osteoblast differentiation, but the exact roles of distinct miR-30 family members during osteogenic differentiation might be different [8]. In addition, Zhang et al. found that, with the stimulation of bone morphogenetic protein-9 (BMP-9), mesenchymal stem cell $\mathrm{C} 3 \mathrm{H} 10 \mathrm{~T} 1 / 2$ could differentiate into osteoblastic cells. In this process, miR-30a played an important negative regulatory role. In detail, the expression of miR-30a in BMP-9stimulated MSCs decreased at early stage and then increased at late stage of osteogenic differentiation. Moreover, miR30a overexpression could affect the proliferation of MSCs, leading to a reduction in the expression of early osteogenesis marker Runx 2 and late osteogenesis marker osteopontin. The mechanism may be related to the altered expression of Runx2, which was regulated by miR-30a [9]. Finally, other literatures also have documented that the expression of miR-30 family members, such as miR-30d and miR-30e, has also changed during the differentiation of MSCs into osteoblastic cells [30]. In conclusion, these studies suggested that miR-30 family participated in bone development. However, the exact role of miR-30 family and its mechanism in promoting embryonic bone formation remain to be elucidated in following studies.

2.2. miR-30 Family and Reproductive System. miR-30 was reported to be highly expressed in both mouse and human testes tissue and associated with the Homeobox protein and $\mathrm{Zn}$ transport, which were critical for male fertility [31], indicating that miR-30 played a role in reproductive development. Fischer et al. further showed that miR-30 family could regulate the generation of recombinant proteins in Chinese hamster ovary cells [32]. In terms of the definite mechanism, their latest research found that S-phase kinase related protein 2 (Skp2) and ubiquitin-conjugating enzyme E2, J1 (Ubej1) were regulated by miR-30 family in Chinese hamster ovary cells. Their data suggested that miR-30 family could affect the expression of recombinant proteins by regulating ubiquitin E3 ligase-Skp2-induced ubiquitin pathway, thereby affecting the development of reproductive system [10]. In addition, other researchers have found that miR-30 family was also robustly expressed in unfertilized rainbow trout eggs, which provided a new point to control the quality of eggs and early embryo formation of rainbow trout in the future [33]. The above studies showed that miR-30 family was involved in the animal reproductive system development, but their role in the development of human reproductive system and the underlying mechanism required further investigation.

2.3. miR-30 Family and Adipogenesis. Recent studies have found that miR-30 family played an important role in adipocyte differentiation. The expression of miR-30 family members vigorously increased in the differentiation of human adipose tissue-derived stem cells into adipocytes [34]. Moreover, the inhibition of miR-30 family members (including miR-30a and miR-30d) could reduce the process of lipogenesis. Conversely, the overexpression of miR-30 family members could promote the process of lipogenesis. The corresponding mechanism may be related to the expression of the transcription factor Runx2, which was a target of miR-30 family [11]. In addition, $\mathrm{Hu}$ et al. found that the expression of miR-30 family members (including miR-30b and miR-30c) was upregulated during adipose differentiation. Moreover, forced expression of miR-30b/c 


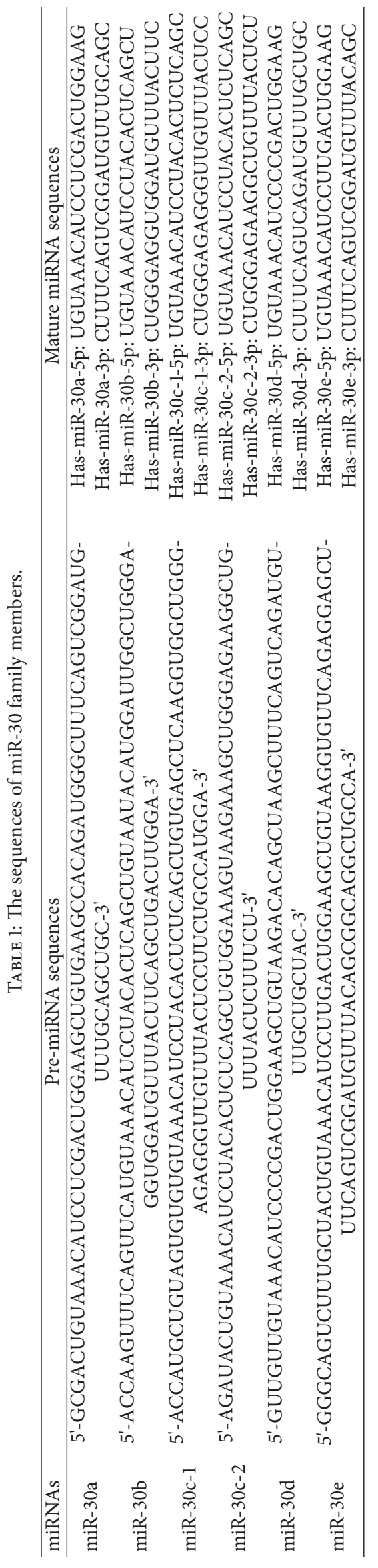


also significantly increased thermogenic gene expression in primary adipocytes. Mechanistic aspect, the knockdown of miR-30 family members (including miR-30b and miR$30 \mathrm{c}$ ), could inhibit the expression of uncoupling protein 1 (UCP1) and cell death-inducing DFFA-like effector a (Cidea) in brown adipocytes, which was related to upregulation of their target RIP140 [12]. Finally, in an in vivo study, Li et al. found an increased expression of miR-30e in animal adipose tissue by using Solexa sequencing [35]. In summary, miR-30 family not only played an important role in adipogenesis but also participated in the regulation of brown adipose tissue function, indicating that it may be a new potential target for regulating lipid metabolism.

2.4. miR-30 Family and the Development of Other Normal Tissues and Organs. Multiple studies have suggested that miR30 family members were involved in the development of other tissues and organs, including pancreas, blood vessels, and intestinal tissues, which showed the extensive roles of miR-30 family. For instance, Joglekar found that the concentration of miR-30 family was high in human islets and miR-30 family had participated in the intracellular response of pancreatic epithelial cells through regulating relative signaling pathways in epithelial mesenchymal transition (EMT) [36]. Bridge et al. found that miR-30 family members (including miR-30b and miR-30c) have taken part in the endothelial cell growth process by regulating the expression of $\delta$-like ligand 4 (DLL4) during angiogenesis [13]. Moreover, Peck et al. reported that the inhibition of miR-30 family in intestinal epithelial cells resulted in a significant decrease in cell proliferation and a significant increase in the differentiation, indicating that miR-30 family had an important regulatory role in this differentiation process [37]. Finally, there were other studies indicating that miR-30b was also involved in mammary gland development and the expression of miR-30b was related to the lactation and involution [38]. Overall, these findings suggested that miR-30 family might take part in the development of multiple tissues and organs; however, the exact mechanisms need to be further elucidated.

\section{3. miR-30 Family and Clinical Diseases}

\section{1. miR-30 Family and Cancer}

3.1.1. miR-30 Family as Tumor Suppressor miRNAs. Current studies have shown that miR-30 family, as tumor suppressor, played important roles in the development of various cancers. For example, Cheng et al. found that miR-30a could inhibit the metastasis and invasion of breast cancer cells by negatively regulating the expression of the vimentin [39]. And Braun et al. reported that miR-30 could reduce the invasive potential of mesenchymal anaplastic thyroid carcinoma-derived cells [40]. Consistently, Zhong et al. reported that the inhibition of miR-30c promoted the invasion of non-small cell lung cancer by promoting EMT process [41]. Furthermore, recent studies have found that miR-30 family could inhibit tumor cell growth, which was related to the change of tumor cell autophagy. For example, Singh et al. found that the restoration of miR-30a weakened the tumorigenesis of medulloblastoma cells, accompanied with a decreased expression in Beclin 1 and the inhibition of autophagy [14]. Moreover, Zhang et al. found that miR-30d could inhibit autophagy of colon cancer cells by directly targeting messenger RNA of autophagy related protein 5 (ATG5), Beclin 1, and phosphoinositide 3-kinase (PI3K), thereby promoting cell apoptosis [15].

3.1.2. miR-30 Family as Oncogenic miRNAs. Similar to other miRNAs, such as miR-7 [42], miR-30 family also played a role, as oncogenic miRNA, in tumorigenesis of some cancers, which reflected the complexities of their biological function. For example, Wang et al. found that the overexpression of miR-30a promoted tumor formation by inhibiting the expression of forkhead box protein L2 (FOXL2) in COV434 cells, accompanied with the upregulation of B-cell lymphoma 2 related protein $\mathrm{A} 1$ (BCL2A1), immediate early response 3 (IER3), and cyclin D2 [16]. Moreover, the level of miR-30a was upregulated in the urine of ovarian serous adenocarcinoma patients [43]. Consistently, knockdown of miR-30a suppressed the malignant phenotypes of ovarian cancer cells in vitro [43]. Most interestingly, Gaziel-Sovran et al. further found that miR-30 family members (including miR-30b and miR-30d) promoted the metastatic behavior of melanoma cells by directly targeting the $\mathrm{N}$-acetyl galactose (GalNAc) transferase GALNT7, resulting in increased synthesis of the immunosuppressive cytokine interleukin-10 (IL-10) and decreased immune cells activation and recruitment [17]. This research work suggested that miR-30 family could contribute to the development of cancer partially through affecting host immune reaction.

In summary, to the contradictory roles of miR-30 family in tumorigenesis, we infer that this may reflect the biological function of miR-30 family, which was related to the different tumor types, the expression level of miR-30 family, and corresponding various target molecules in distinct types of cancers. Therefore, it is necessary to further elucidate the definite function and its mechanism of miR-30 family in related cancers.

3.2. miR-30 Family and Cardiovascular Disease. Nakagawa et al. found that the expression of miR-30, which could target cardiac GalNAc-transferase (GALNT) 1 and 2 expression, was abundant in myocardium of healthy hearts but decreased obviously in failing hearts [44]. Furthermore, miR-30e mimic treatment resulted in downregulation of Beclin 1 via inhibiting its $3^{\prime}$ UTR activity and protected primary cardiomyocytes against apoptosis in vitro. Conversely, miR-30e silencing promoted cardiomyocytes apoptosis by elevating the expression of angiotensin-converting enzyme 2 (ACE2), thereby reducing the apoptosis of cardiomyocytes [18]. However, it would be noticed that, in animal cardiac ischemic injury model, the silence of miR-30 family could elevate the levels of $\mathrm{CSE}$ and $\mathrm{H}_{2} \mathrm{~S}$ and protect cardiomyocytes against hypoxiainduced injury in vivo, indicating the promising therapeutic potential of miR-30 family in ischemic heart diseases [45]. Thus, to this phenomenon, we presume that the controversial 
finding might be related to the difference on in vitro and in vivo experimental setting.

In addition, Zhang et al. found that high fat-induced miR-30 upregulation could impair the protective effects of endothelial cell autophagy against atherosclerosis through suppressing protein translation of ATG6 [19]. Finally, other studies showed that miR-30a could downregulate endothelial DLL4 expression, thereby controlling the behavior of tip cells, indicating that miR-30 family was also related to the rarefaction process and hypertension [20]. Hence, the investigation of miR-30 family is much helpful for the illustration on the pathogenesis and the development of novel therapeutic strategies of cardiovascular diseases.

3.3. miR-30 Family and Renal Disease. miR-30 family members are also involved in the pathological process of renal diseases [46]. For example, Wu et al. found that glucocorticoidsustained miR-30 expression was associated with reduced Notchl activation and alleviated podocytes damage, accompanied with altered expression of Notch1 and p53 [21], indicating the important role of miR-30 family in renal diseases. In line with this finding, Wu et al. further found that some critical components of calcium/calcineurin signaling, including TRPC6, PPP3CA, PPP3CB, PPP3R1, and NFATC3, were the targets of miR-30 family. Moreover, podocytespecific expression of the miR-30 sponge in mice increased calcium/calcineurin pathway component protein expression and calcineurin activity [47]. Notably, recent evidence further showed that transforming growth factor- $\beta$ (TGF- $\beta$ ) could inhibit the expression of miR-30d through a Smad2/3HDAC3-NcoR repression complex and provide new insights into a potential target for the treatment of podocytes injuryassociated glomerulopathies [22]. In addition, it has been reported that the levels of miR-30 family members (including miR-30a, miR-30c, and miR-30e) increased in the plasma of contrast-induced nephropathy (CIN) rats compared with their levels in non-CIN control rats, suggesting that miR-30 family might serve as early biomarkers and target candidates for CIN [48]. Moreover, miR-30c was also involved in the regulation of renal tubular cell apoptosis in cisplatin-induced nephrotoxicity, which provided a new therapeutic strategy for the improvement of cisplatin-induced nephrotoxicity [49].

Combining these studies suggested that miR-30 family played an important regulatory role in the pathogenesis of various kidney diseases and may be a potential target for treatment and diagnosis of relative diseases.

3.4. miR-30 Family and Other Clinical Diseases. Up to now, a large number of studies have demonstrated that miR-30 family has been involved in the pathogenesis of many other diseases, such as osteoarthritis, fibrosis, and hepatitis [50]. For example, Li et al. found that miR-30b was involved in the pathogenesis of osteoarthritis and its expression level in the articular cartilage increased robustly compared with normal people [23]. As for fibrosis diseases, Tu et al. reported that miR-30 could inhibit the occurrence of liver fibrosis, potentially through inhibiting its target molecule TGF- $\beta$ [24].
Berschneider et al. further found that miR-30a could reverse WNT1-induced signaling pathway protein 1 (WISP1) mRNA expression in lung fibrosis, thereby affecting the process of lung fibrosis [25]. Importantly, miR-30 family was also reported to be involved in immune responses and related diseases. For example, miR-30a exhibited low expression in Mycobacterium tuberculosis- (MTB-) infected patients and the overexpression of miR-30 suppressed the ability of host cells to eradicate intracellular MTB [51]. Interestingly, the most recent evidence further showed that, in uninfected THP-1 cells, miR-30a could inhibit the expression of myeloid differentiation factor 88 (MyD88) and subsequently reduced the TLR signaling and cytokine expression, indicating that miR-30a participated in MTB-induced immune responses via regulating TLR/MyD88 activation and cytokine expression [26]. Besides, other studies have also found that miR30 family was related to the pathogenesis of other diseases such as allergic rhinitis [52] and Alzheimer's disease [53]. However, the related mechanisms remain to be elucidated.

\section{Conclusion}

Current studies have shown that miR-30 family, as a member of miRNA family, played an important and promising role in the development of tissues and organs and various clinical diseases. Although existent investigations have revealed the related molecular mechanisms (Table 2 ), there are still many critical problems that need to be further illustrated in the future, such as (a) how to explore the exact mechanism of distinct miR-30 family members on regulating the development of different tissues and organs, (b) what are the exact roles of miR-30 family members in different types of tumors, (c) how to utilize the difference of miR-30 family members to perform subsequent targeted treatment, and (d) what are the exact roles of miR-30 family members in immune organs development and diseases-related immune responses. We believe that the elucidation of these representative questions not only will help to deepen the understanding of the biological function of miR-30 family but also will bring about a novel insight into diagnosis and molecular targeted therapy of related clinical diseases.

\section{Conflicts of Interest}

All authors declare that the research was conducted in the absence of any commercial or financial relationships that could be construed as potential conflicts of interest.

\section{Acknowledgments}

This manuscript was supported by the National Natural Science foundation of China (31370918), Program for New Century Excellent Talents in University, Ministry of Education of China (NCET-12-0661), Program for High Level Innovative Talents in Guizhou Province (QKH-RC-20164031), Program for Excellent Young Talents of Zunyi Medical University (15ZY-001), Program for Science and Technology 
TABLE 2: The targets of miR-30 family members in tissue and organ development and clinical diseases.

\begin{tabular}{|c|c|c|c|c|c|}
\hline & Types & miRNAs & Targets & Cells/Models & References \\
\hline \multirow{7}{*}{$\begin{array}{l}\text { Tissue and organ } \\
\text { development }\end{array}$} & \multirow{3}{*}{ Bone tissue } & miR-30a, miR-30d & BMP2 & $\mathrm{C} 2 \mathrm{C} 12$ cells & [7] \\
\hline & & miR-30a, miR-30b, & Smad1, Runx2 & MC3T3-E1 cells & [8] \\
\hline & & miR-30a, & Runx2 & C3H10T1/2 cells & [9] \\
\hline & $\begin{array}{l}\text { Reproductive } \\
\text { system }\end{array}$ & miR-30 family & Skp2, Ubej1 & CHO cells & {$[10]$} \\
\hline & \multirow{2}{*}{ Adipose tissue } & miR-30a, miR-30d & Runx2 & hMADS cells & [11] \\
\hline & & miR-30b, miR-30c & $\begin{array}{l}\text { UCP1, Cidea, } \\
\text { RIP140 }\end{array}$ & C57BJ6 mice & {$[12]$} \\
\hline & Vessel & miR-30b, miR-30c & DLL4 & LECs, HUVECs & {$[13]$} \\
\hline \multirow{16}{*}{ Related diseases } & \multirow{2}{*}{$\begin{array}{l}\text { Tumorigenesis (as } \\
\text { tumor suppressor) }\end{array}$} & miR-30a & Beclin1 & $\begin{array}{l}\text { Daoy, D283, D425 } \\
\text { cells }\end{array}$ & [14] \\
\hline & & miR-30d & $\begin{array}{l}\text { ATG5, PI3K, } \\
\text { Beclin1 }\end{array}$ & $\begin{array}{l}\text { HCT15, HCT116, } \\
\text { HT-29, DLD-1, } \\
\text { SW480 cells }\end{array}$ & {$[15]$} \\
\hline & \multirow{2}{*}{$\begin{array}{l}\text { Tumorigenesis (as } \\
\text { oncogene) }\end{array}$} & miR-30a & $\begin{array}{l}\text { FOXL2, BCLA1, } \\
\text { IER3, cyclin D2 }\end{array}$ & COV434 cells & [16] \\
\hline & & miR-30b, miR-30d & GALNT7 & $\begin{array}{l}\text { Melanoma cells, } \\
\text { clinical specimens }\end{array}$ & {$[17]$} \\
\hline & \multirow{3}{*}{$\begin{array}{l}\text { Cardiovascular } \\
\text { disease }\end{array}$} & miR-30e & ACE2 & $\begin{array}{l}\text { Sprague Dawley } \\
\text { rats }\end{array}$ & {$[18]$} \\
\hline & & $\operatorname{miR}-30$ & ATG6 & $\begin{array}{c}\text { ApoE }{ }^{(-/-)} \text {mice, } \\
\text { HAECs }\end{array}$ & [19] \\
\hline & & miR-30a & DLL4 & Zebrafish & {$[20]$} \\
\hline & \multirow{2}{*}{ Renal disease } & miR-30 family & Notch1, p53 & $\begin{array}{l}\text { Wistar rats, human } \\
\text { podocytes, clinical } \\
\text { specimens }\end{array}$ & {$[21]$} \\
\hline & & miR-30d & TGF- $\beta$ & HEK293 cells & {$[22]$} \\
\hline & Osteoarthritis & miR-30b & ERG & $\begin{array}{l}\text { SW1353 cells, } \\
\text { clinical specimens }\end{array}$ & [23] \\
\hline & Hepatic fibrosis & $\operatorname{miR}-30$ & TGF- $\beta$ & $\begin{array}{l}\text { ICR mice, HSCs } \\
\text { Sprague Dawley }\end{array}$ & {$[24]$} \\
\hline & Pulmonary fibrosis & miR-30a & WISP1 & $\begin{array}{l}\text { rats, primary } \\
\text { human lung } \\
\text { fibroblasts }\end{array}$ & {$[25]$} \\
\hline & \multirow[t]{2}{*}{ Tuberculosis } & miR-30a & MyD88 & THP-1 cells & [26] \\
\hline & & miR-30c & REDD1 & $\begin{array}{l}\text { hFOB cells, } \mathrm{CD} 34^{+} \\
\text {cells }\end{array}$ & [27] \\
\hline & \multirow[t]{2}{*}{ Radiation damage } & miR-30b, miR-30c & $N F-\kappa B$ & $\begin{array}{l}\text { CD2F1 mice, } \\
\text { CD34 }{ }^{+} \text {cells }\end{array}$ & {$[28]$} \\
\hline & & miR-30b, miR-30c & Mcl-1 & $\begin{array}{l}\text { CD2F1 mice, } \\
\text { CD } 34^{+} \text {cells }\end{array}$ & [29] \\
\hline
\end{tabular}

Notes. BMP2: bone morphogenetic protein-2; Smad1: SMAD family member 1; Runx2: runt-related transcription factor 2; Skp2: S-phase kinase related protein 2; Ubej1: ubiquitin-conjugating enzyme E2, J1; UCP1: uncoupling protein 1; Cidea: cell death-inducing DFFA-like effector a; DLL4: $\delta$-like ligand 4; $A T G 5$ : autophagy related protein 5; PI3K: phosphoinositide 3-kinase; FOXL2: forkhead box protein L2; BCLA1: B-cell lymphoma 2 related protein A1; IER3: immediate early response 3; IL-10: interleukin-10; ACE2: angiotensin-converting enzyme 2; ATG6: autophagy related protein 6; TGF- $\beta$ : transforming growth factor- $\beta$; ERG: EST-related genes; WISP1: WNT1-induced signaling pathway protein 1; MyD88: bone marrow differentiation factor 88; REDD1: DNA damage inducible transcript 4; NF-KB: nuclear factor kappa B; Mcl-1: BCL2 family apoptosis regulator.

Joint Fund Project in Zunyi Science and Technology Bureau, and Zunyi Medical University (ZSKH-SZ-2016-38).

\section{References}

[1] D. P. Bartel, “Metazoan MicroRNAs," Cell, vol. 173, no. 1, pp. $20-$ 51, 2018.

[2] K. Gagnon, L. Li, Y. Chu, B. Janowski, and D. Corey, "RNAi factors are present and active in human cell nuclei," Cell Reports, vol. 6, no. 1, pp. 211-221, 2014.
[3] S. Bottini, N. Hamouda-Tekaya, R. Mategot et al., "Posttranscriptional gene silencing mediated by microRNAs is controlled by nucleoplasmic Sfpq," Nature Communications, vol. 8, no. 1, article no. 1189, 2017.

[4] F. Wang, J. Wang, J. He et al., "Serum miRNAs miR-23a, 206, and 499 as Potential Biomarkers for Skeletal Muscle Atrophy," BioMed Research International, vol. 2017, pp. 1-9, 2017.

[5] X. Xu, J. Lu, F. Wang et al., "Dynamic Changes in Plasma MicroRNAs Have Potential Predictive Values in Monitoring Recurrence and Metastasis of Nasopharyngeal Carcinoma," BioMed Research International, vol. 2018, pp. 1-10, 2018. 
[6] S. Yang, S. Yang, D. Wang et al., "The miR-30 family: Versatile players in breast cancer," Tumor Biology, vol. 39, no. 3, p. 101042831769220, 2017.

[7] Z. Li, M. Q. Hassan, S. Volinia et al., "A microRNA signature for a BMP2-induced osteoblast lineage commitment program," Proceedings of the National Acadamy of Sciences of the United States of America, vol. 105, no. 37, pp. 13906-13911, 2008.

[8] T. Wu, H. Zhou, Y. Hong, J. Li, X. Jiang, and H. Huang, "miR-30 family members negatively regulate osteoblast differentiation," The Journal of Biological Chemistry, vol. 287, no. 10, pp. 75037511, 2012.

[9] R. Zhang, Y. Weng, B. Li et al., "BMP9-induced osteogenic differentiation is partially inhibited by miR-30a in the mesenchymal stem cell line C3H10T1/2," Journal of Molecular Histology, vol. 46, no. 4-5, pp. 399-407, 2015.

[10] S. Fischer, S. Mathias, S. Schaz et al., "Enhanced protein production by microRNA-30 family in CHO cells is mediated by the modulation of the ubiquitin pathway," Journal of Biotechnology, vol. 212, pp. 32-43, 2015.

[11] L.-E. Zaragosi, B. Wdziekonski, K. L. Brigand et al., "Small RNA sequencing reveals miR-642a-3p as a novel adipocytespecific microRNA and miR-30 as a key regulator of human adipogenesis," Genome Biology, vol. 12, no. 7, article R64, 2011.

[12] F. Hu, M. Wang, T. Xiao et al., "miR-30 Promotes Thermogenesis and the Development of Beige Fat by Targeting RIP140," Diabetes, vol. 64, no. 6, pp. 2056-2068, 2015.

[13] G. Bridge, R. Monteiro, S. Henderson et al., "The microRNA30 family targets DLL4 to modulate endothelial cell behavior during angiogenesis," Blood, vol. 120, no. 25, pp. 5063-5072, 2012.

[14] S. V. Singh, A. N. Dakhole, A. Deogharkar et al., "Restoration of miR-30a expression inhibits growth, tumorigenicity of medulloblastoma cells accompanied by autophagy inhibition," Biochemical and Biophysical Research Communications, vol. 491, no. 4, pp. 946-952, 2017.

[15] R. Zhang, J. Xu, J. Zhao, and J. Bai, "Mir-30d suppresses cell proliferation of colon cancer cells by inhibiting cell autophagy and promoting cell apoptosis," Tumor Biology, vol. 39, no. 6, 2017.

[16] T. Wang, F. Li, and S. Tang, "MiR-30a upregulates BCL2A1, IER3 and cyclin D2 expression by targeting FOXL2," Oncology Letters, vol. 9, no. 2, pp. 967-971, 2015.

[17] A. Gaziel-Sovran, M. F. Segura, R. Di Micco et al., "MiR30b/30d Regulation of GalNAc Transferases Enhances Invasion and Immunosuppression during Metastasis," Cancer Cell, vol. 20, no. 1, pp. 104-118, 2011.

[18] L. Lai, J. Chen, N. Wang, G. Zhu, X. Duan, and F. Ling, "MiRNA-30e mediated cardioprotection of ACE2 in rats with Doxorubicin-induced heart failure through inhibiting cardiomyocytes autophagy," Life Sciences, vol. 169, pp. 69-75, 2017.

[19] T. Zhang, F. Tian, J. Wang, J. Jing, S.-S. Zhou, and Y.-D. Chen, "Endothelial cell autophagy in atherosclerosis is regulated by miR-30-mediated translational control of ATG6," Cellular Physiology and Biochemistry, vol. 37, no. 4, pp. 1369-1378, 2015.

[20] Q. Jiang, M. Lagos-Quintana, D. Liu et al., "MiR-30a regulates endothelial tip cell formation and arteriolar branching," Hypertension, vol. 62, no. 3, pp. 592-598, 2013.

[21] J. Wu, C. Zheng, Y. Fan et al., "Downregulation of MicroRNA-30 facilitates podocyte injury and is prevented by glucocorticoids," Journal of the American Society of Nephrology, vol. 25, no. 1, pp. 92-104, 2014.
[22] L. Liu, W. Lin, Q. Zhang, W. Cao, and Z. Liu, “TGF- $\beta$ induces miR-30d down-regulation and podocyte injury through Smad2/3 and HDAC3-associated transcriptional repression," Journal of Molecular Medicine, vol. 94, no. 3, pp. 291-300, 2016.

[23] L. Li, C. Yang, X. Liu et al., "Elevated expression of microRNA$30 \mathrm{~b}$ in osteoarthritis and its role in ERG regulation of chondrocyte," Biomedicine \& Pharmacotherapy, vol. 76, pp. 94-99, 2015.

[24] X. Tu, X. Zheng, H. Li et al., "MicroRNA-30 protects against carbon tetrachlorideinduced liver fibrosis by attenuating transforming growth factor beta signaling in hepatic stellate cells," Toxicological Sciences, vol. 146, no. 1, Article ID kfv081, pp. 157169, 2015.

[25] B. Berschneider, D. C. Ellwanger, H. A. Baarsma et al., "miR92a regulates TGF- $\beta 1$-induced WISP1 expression in pulmonary fibrosis," The International Journal of Biochemistry \& Cell Biology, vol. 53, pp. 432-441, 2014.

[26] Y. Wu, Q. Sun, and L. Dai, "Immune regulation of miR-30 on the Mycobacterium tuberculosis-induced TLR/Myd88 signaling pathway in THP-1 cells," Experimental and Therapeutic Medicine, vol. 14, no. 4, pp. 3299-3303, 2017.

[27] X. H. Li, C. T. Ha, D. Fu, and M. Xiao, "Micro-RNA30c Negatively Regulates REDD1 Expression in Human Hematopoietic and Osteoblast Cells after Gamma-Irradiation," PLoS ONE, vol. 7, no. 11, Article ID e48700, 2012.

[28] X. H. Li, C. T. Ha, D. Fu et al., "Delta-tocotrienol suppresses radiation-induced microRNA-30 and protects mice and human $\mathrm{CD}_{3}{ }^{+}$cells from radiation injury," PLoS ONE, vol. 10, no. 3, Article ID e0122258, 2015.

[29] X. H. Li, C. T. Ha, and M. Xiao, "MicroRNA-30 inhibits antiapoptotic factor Mcl-1 in mouse and human hematopoietic cells after radiation exposure," Apoptosis, vol. 21, no. 6, pp. 708720, 2016.

[30] T. Eguchi, K. Watanabe, E. S. Hara, M. Ono, T. Kuboki, and S. K. Calderwood, "OstemiR: a novel panel of microRNA biomarkers in osteoblastic and osteocytic differentiation from mesencymal stem cells," PLoS ONE, vol. 8, no. 3, Article ID e58796, 2013.

[31] M. J. Madison-Villar and P. Michalak, "Misexpression of testicular microrna in sterile xenopus hybrids points to tetrapodspecific micrornas associated with male fertility," Journal of Molecular Evolution, vol. 73, no. 5-6, pp. 316-324, 2011.

[32] S. Fischer, T. Buck, A. Wagner et al., "A functional high-content miRNA screen identifies miR-30 family to boost recombinant protein production in CHO cells," Biotechnology Journal, vol. 9, no. 10, pp. 1279-1292, 2014.

[33] H. Ma, M. Hostuttler, H. Wei, C. E. Rexroad III, and J. Yao, "Characterization of the rainbow trout egg microRNA transcriptome," PLoS ONE, vol. 7, no. 6, Article ID e39649, 2012.

[34] C. Shi, M. Zhang, M. Tong et al., "MiR-148a is associated with obesity and modulates adipocyte differentiation of mesenchymal stem cells through wnt signaling," Scientific Reports, vol. 5, article 9930, 2015.

[35] G. Li, Y. Li, X. Li, X. Ning, M. Li, and G. Yang, "MicroRNA identity and abundance in developing swine adipose tissue as determined by solexa sequencing," Journal of Cellular Biochemistry, vol. 112, no. 5, pp. 1318-1328, 2011.

[36] M. V. Joglekar, D. Patil, V. M. Joglekar et al., “The miR-30 family microRNAs confer epithelial phenotype to human pancreatic cells," Islets, vol. 1, no. 2, pp. 137-147, 2009.

[37] B. C. E. Peck, J. Sincavage, S. Feinstein et al., "miR-30 family controls proliferation and differentiation of intestinal epithelial cell models by directing a broad gene expression program that 
includes SOX9 and the ubiquitin ligase pathway," The Journal of Biological Chemistry, vol. 291, no. 31, pp. 15975-15984, 2016.

[38] S. Le Guillou, N. Sdassi, J. Laubier et al., "Overexpression of miR-30b in the Developing Mouse Mammary Gland Causes a Lactation Defect and Delays Involution," PLOS ONE, vol. 7, no. 9, Article ID e45727, 2012.

[39] C.-W. Cheng, H.-W. Wang, C.-W. Chang et al., "microRNA30a inhibits cell migration and invasion by downregulating vimentin expression and is a potential prognostic marker in breast cancer," Breast Cancer Research and Treatment, vol. 134, no. 3, pp. 1081-1093, 2012.

[40] J. Braun, C. Hoang-Vu, H. Dralle, and S. Hüttelmaier, "Downregulation of microRNAs directs the EMT and invasive potential of anaplastic thyroid carcinomas," Oncogene, vol. 29, no. 29, pp. 4237-4244, 2010.

[41] Z. Zhong, Y. Xia, P. Wang, B. Liu, and Y. Chen, "Low expression of microRNA-30c promotes invasion by inducing epithelial mesenchymal transition in non-small cell lung cancer," Molecular Medicine Reports, vol. 10, no. 5, pp. 2575-2579, 2014.

[42] J. Zhao, Y. Tao, Y. Zhou et al., "MicroRNA-7: a promising new target in cancer therapy," Cancer Cell International, vol. 15, no. $1,2015$.

[43] J. Zhou, G. Gong, H. Tan et al., "Urinary microRNA-30a-5p is a potential biomarker for ovarian serous adenocarcinoma," Oncology Reports, vol. 33, no. 6, pp. 2915-2923, 2015.

[44] Y. Nakagawa, T. Nishikimi, K. Kuwahara et al., "MiR30GALNT1/2 axis-mediated glycosylation contributes to the increased secretion of inactive human prohormone for brain natriuretic peptide (proBNP) from failing hearts," Journal of the American Heart Association, vol. 6, no. 2, Article ID e003601, 2017.

[45] Y. Shen, Z. Shen, L. Miao et al., "MiRNA-30 family inhibition protects against cardiac ischemic injury by regulating cystathionine- $\gamma$-lyase expression," Antioxidants \& Redox Signaling, vol. 22, no. 3, pp. 224-240, 2015.

[46] S. Shi, L. Yu, C. Chiu et al., "Podocyte-selective deletion of dicer induces proteinuria and glomerulosclerosis," Journal of the American Society of Nephrology, vol. 19, no. 11, pp. 2159-2169, 2008.

[47] J. Wu, C. Zheng, X. Wang et al., "MicroRNA-30 family members regulate calcium/calcineurin signaling in podocytes," The Journal of Clinical Investigation, vol. 125, no. 11, pp. 4091-4106, 2015.

[48] A. Gutiérrez-Escolano, E. Santacruz-Vázquez, and F. GómezPérez, "Dysregulated microRNAs involved in contrast-induced acute kidney injury in rat and human," Renal Failure, vol. 37, no. 9, pp. 1498-1506, 2015.

[49] B. Du, X. Dai, S. Li et al., "MiR-30c regulates cisplatin-induced apoptosis of renal tubular epithelial cells by targeting Bnip3L and Hspa5," Cell Death \& Disease, vol. 8, no. 8, p. e2987, 2017.

[50] C. Scagnolari, P. Zingariello, J. Vecchiet et al., "Differential expression of interferon-induced microRNAs in patients with chronic hepatitis $\mathrm{C}$ virus infection treated with pegylated interferon alpha," Virology Journal, vol. 7, article no. 311, 2010.

[51] Z. Chen, T. Wang, Z. Liu et al., "Inhibition of autophagy by MiR$30 \mathrm{~A}$ induced by Mycobacteria tuberculosis as a possible mechanism of immune escape in human macrophages," Japanese Journal of Infectious Diseases, vol. 68, no. 5, pp. 420-424, 2015.

[52] G. Wu, G. Yang, R. Zhang et al., "Altered microRNA expression profiles of extracellular vesicles in nasal mucus from patients with allergic rhinitis," Allergy, Asthma \& Immunology Research, vol. 7, no. 5, pp. 449-457, 2015.
[53] Q. Y. Liu, M. N. V. Chang, J. X. Lei et al., "Identification of microRNAs involved in Alzheimer's progression using a rabbit model of the disease," American Journal of Neurodegenerative Diseases, vol. 3, no. 1, pp. 33-44, 2014. 


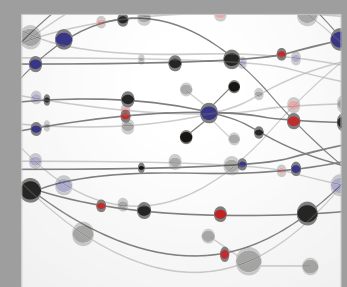

The Scientific World Journal
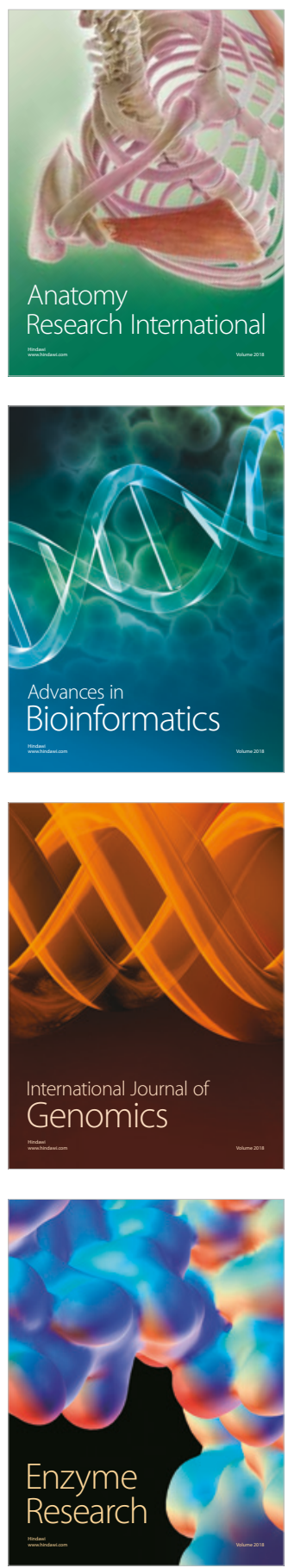
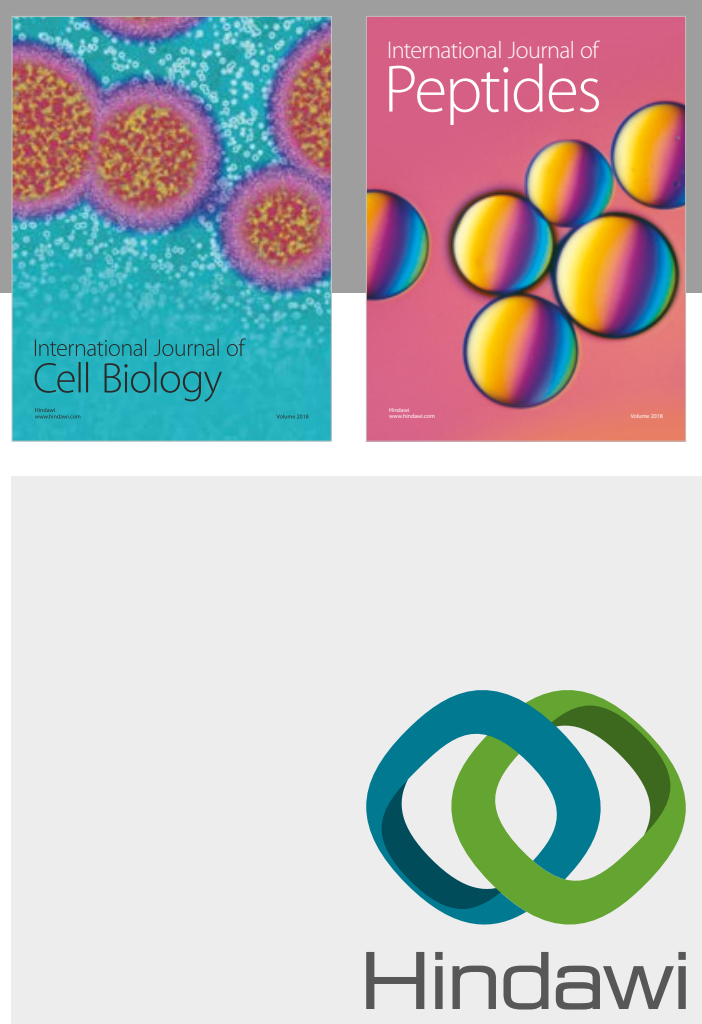

Submit your manuscripts at

www.hindawi.com
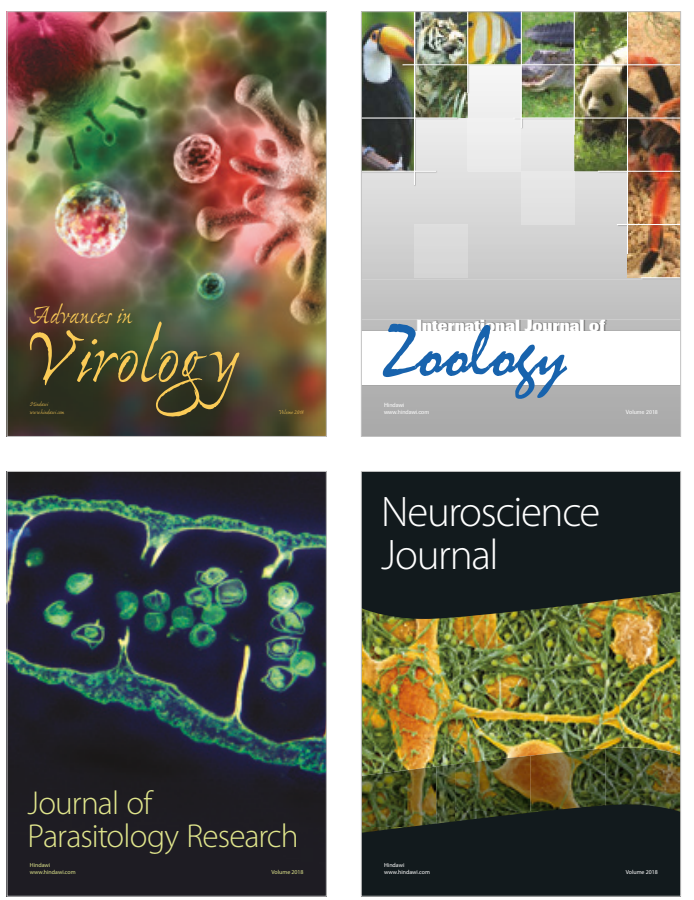
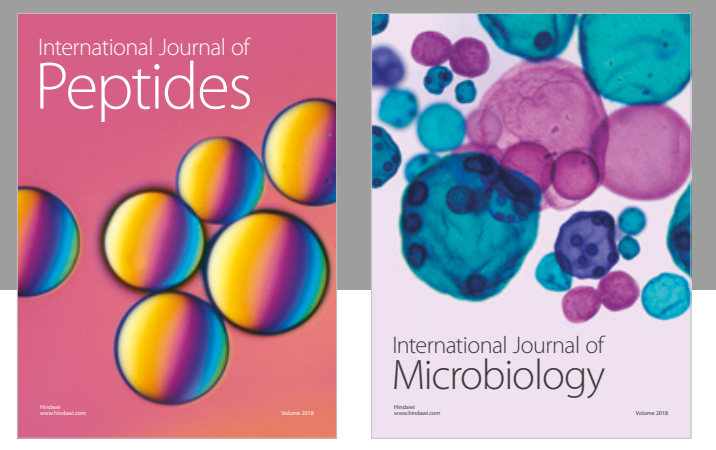

nternational Journal of Microbiology
Journal of
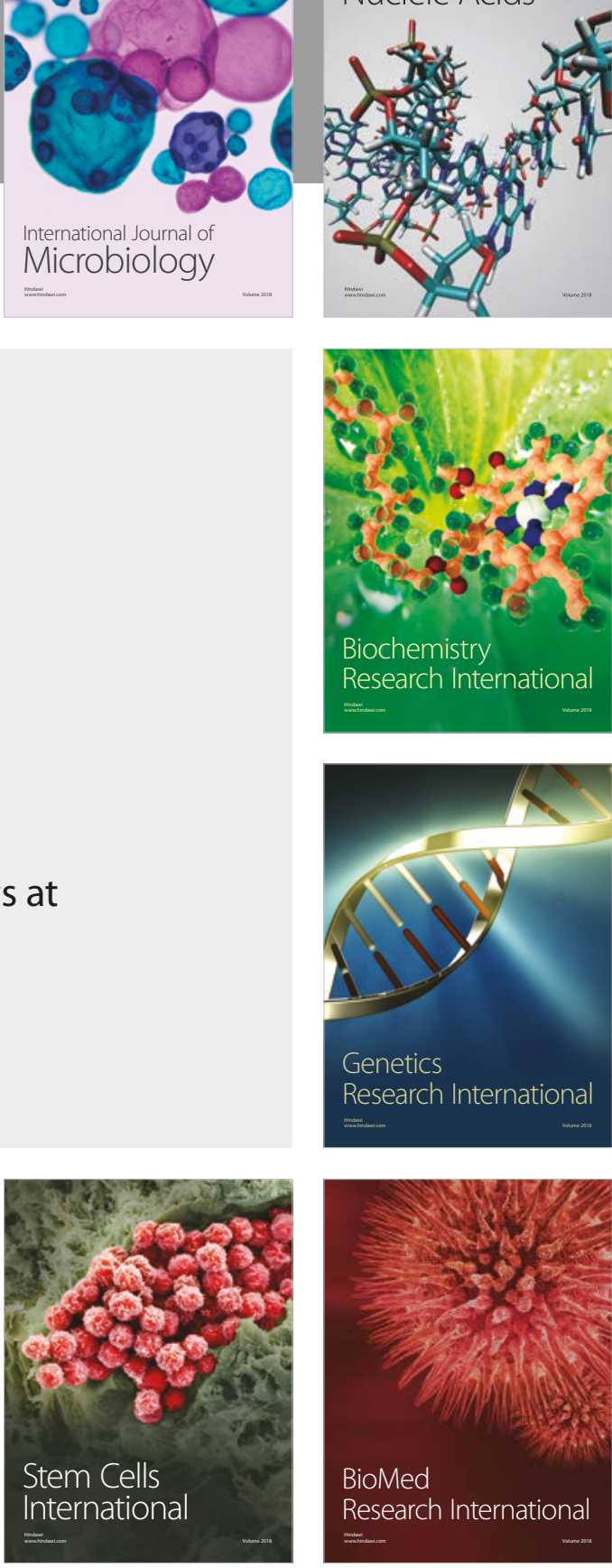
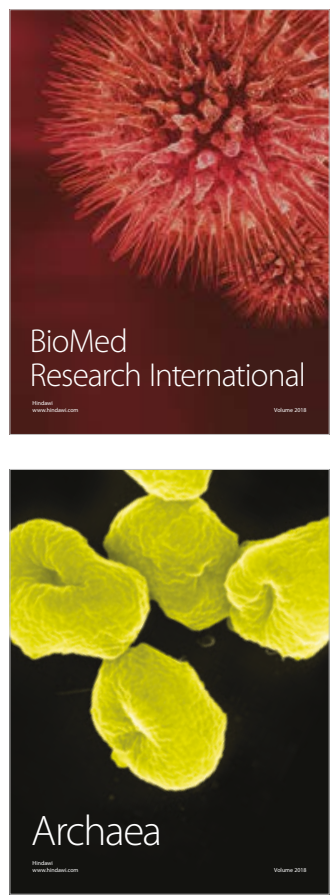